\title{
Bactérias Gram positivas veiculadas por formigas em ambiente hospitalar de Porto Velho, Estado de Rondônia, Brasil
}

Gram-positive bacteria carried by ants in hospital environment in the City of Porto Velho, Rondônia State, Brazil

Bacterias Gram-positivas vehiculadas por hormigas en ambiente hospitalario en la Ciudad de Porto Velho, Estado de Rondônia, Brasil

Gabriel de Deus Vieira

Departamento de Microbiologia, Faculdade São Lucas, Porto Velho, Rondônia, Brasil

Thaianne da Cunha Alves

Departamento de Microbiologia, Faculdade São Lucas, Porto Velho, Rondônia, Brasil

Olívia Bezerra da Silva

Departamento de Microbiologia, Faculdade São Lucas, Porto Velho, Rondônia, Brasil
Flávio Aparecido Terassini

Departamento de Entomologia, Faculdade São Lucas, Porto Velho, Rondônia, Brasil

Nilson Cardoso Paniágua

Departamento de Medicina, Faculdade São Lucas, Porto Velho, Rondônia, Brasil

Carolina Bioni Garcia Teles

Fundação Oswaldo Cruz, Fiocruz Rondônia, Porto Velho, Rondônia, Brasil

\section{RESUMO}

As formigas são consideradas insetos vetores de várias espécies de patógenos e apresentam grande adaptabilidade a diversos tipos de ambientes. Por essa razão podem oferecer risco a pacientes imunodeprimidos, em ambiente hospitalar. O objetivo deste estudo foi verificar o perfil das bactérias Gram positivas veiculadas por formicídeos em ambiente hospitalar. Os insetos foram coletados na sala de emergência, no setor de pneumologia e no de gastroenterologia em um hospital público de Porto Velho, Estado de Rondônia, Brasil, no período de março a junho de 2012. As bactérias isoladas foram caracterizadas quanto à coloração de Gram, aos testes para identificação de bactérias do gênero Staphylococcus, Streptococcus e Micrococcus e quanto ao perfil de suscetibilidade a antimicrobianos. Entre as 130 formigas capturadas, $62 \%$ das cepas extraídas das formigas foram identificadas como pertencentes ao gênero Staphylococcus, 25\% Streptococcus e 13\% Micrococcus. Em relação à resistência aos antibióticos, $83 \%$ das cepas foram resistentes à oxacilina e $50 \%$ à vancomicina. Conclui-se que as formigas apresentaram grande potencial como veiculadoras mecânicas de bactérias, sugerindo o risco de infecção nosocomial e a permanência de cepas com alta resistência no ambiente hospitalar.

Palavras-chave: Vetores de Doenças; Infecção Hospitalar; Testes de Sensibilidade Microbiana.

\section{INTRODUÇÃO}

O processo de urbanização promoveu o aumento de doenças causadas e/ou transmitidas por artrópodes, entre esses, as formigas, um grupo que obteve melhor adaptação ao ambiente urbano, devido à grande disponibilidade de abrigo e alimento para si, o que facilita seu estabelecimento no ambiente e sua proliferação'. É importante ressaltar que, atualmente, cerca de 12.500 espécies de formigas já foram descritas, mas estima-se a existência de cerca de 21 mil espécies, e, dessas, menos

\footnotetext{
Correspondência / Correspondence / Correspondencia:

Gabriel de Deus Vieira

Departamento de Microbiologia, Faculdade São Lucas

Rua Alexandre Guimarães 1927. Bairro: Areal

CEP: 76804-373 Porto Velho-Rondônia-Brasil

Tel.: +55 (69) $3211-8046$

E-mail: gabrielvieira.mg@hotmail.com
}

de 20 espécies podem ser classificadas como pragas urbanas no Brasil2.

As formigas realizam simbiose com bactérias, sendo consideradas vetores mecânicos de várias espécies desses microrganismos ${ }^{3,4}$. Além disso, possuem uma grande capacidade de locomoção, chegando a percorrer $3 \mathrm{~cm}$ por segundo, e, por isso, podem transitar em vários locais, como UTI, leitos, cozinhas, salas cirúrgicas e outros ambientes hospitalares, muitas vezes sem serem notadas. Desta forma, representam um fator de risco à saúde pública, uma vez que aumentam o risco de infecções hospitalares 5 .

Sua presença nesse tipo de local pode ocorrer devido à estrutura arquitetônica dos hospitais, a sua localização próxima a residências, às embalagens de alguns medicamentos que podem trazer ninhos de formigas e ao grande fluxo de pessoas e alimentos que servem como atrativo para elas 6 . 
controle das formigas é muito difícil, isso porque o conhecimento de sua biologia em ambientes não naturais ainda é muito escasso. Além do mais, não se pode adotar estratégias uniformes devido a sua diversidade e a sua distribuição, que variam muito de hospital para hospital ${ }^{7}$.

Entre os microrganismos que podem ser transportados por formicídeos, destaca-se o estafilococo, que é uma das bactérias que geralmente realiza simbiose com esses insetos, sendo um importante patógeno do homem. Além disso, a bactéria da espécie Staphylococcus aureus já foi descrita como parcialmente resistente à vancomicina e a outros antibióticos. Também já foram encontrados gêneros de outras bactérias carreadas por estes artrópodes, como, por exemplo, Serratia, Klebsiella, Acinetobacter, Enterobacter, Salmonella, Escherichia e Enterococcus ${ }^{8,9}$.

As pesquisas sobre as formigas no Brasil são recentes, tendo o seu início na década de 1980. Desde então, os trabalhos realizados em hospitais revelaram que - País tem uma grande biodiversidade de formigas, quando comparado com outros países, tais como os Estados Unidos e os países da Europa ${ }^{7}$.

Várias cepas bacterianas já se tornaram resistentes aos antibióticos devido ao seu uso indiscriminado. Os antimicrobianos devem ser utilizados de forma consciente, preconizando os antibióticos com menor espectro para um determinado patógeno, evitando a resistência dessa droga a uma determinada bactéria ${ }^{10}$.

Tendo em vista a relevância que a contaminação por esses insetos pode assumir em hospitais, foi conduzido este estudo com o objetivo de identificar bactérias do gênero Staphylococcus ou cocos Gram positivos que as formigas transportam em um ambiente hospitalar de Porto Velho, Estado de Rondônia, e avaliar a resistência antimicrobiana.

\section{MATERIAIS E MÉTODOS}

As formigas foram coletadas em um hospital da rede pública de Porto Velho, no período de março a junho de 2012. Os setores onde houve a captura foram: sala de emergência, setor de pneumologia e setor de gastroenterologia. Foi utilizado swab estéril umedecido em soro fisiológico para a coleta dos insetos, que foram transferidos, em grupos de dez indivíduos, para tubos de ensaio. Os tubos de ensaio continham TSB suplementado com 7,5\% de $\mathrm{NaCl}$, facilitando assim o transporte até o Laboratório de Microbiologia da Faculdade São Lucas, localizada na mesma cidade. No laboratório, alíquotas do meio foram semeadas em placas de Petri com meio Ágar Manitol durante $24 \mathrm{~h}$. Após esse período, as colônias isoladas foram utilizadas para a coloração de Gram e testes de caracterização dos gêneros Staphylococcus, Streptococcus e Micrococcus.

Nas cepas que apresentaram crescimento, foi realizado o teste do antibiograma, sendo utilizados os antibióticos: oxalicina $(1 \mu \mathrm{g})$ e vancomicina $(30 \mu \mathrm{g})$. Foi utilizada a padronização com o tubo número 2 da escala de MacFarland e o meio utilizado para o antibiograma foi o Mueller-Hinton.

\section{RESULTADOS}

Foram coletadas 130 formigas (13 grupos), todas pertencentes à espécie Tapinoma melanocephalum. Observa-se a ocorrência de uma única espécie na área de estudo, embora as coletas tenham sido realizadas em três ambientes intra-hospitalares. Desse total, 30 formigas (três grupos) foram capturadas na sala de emergência, 50 (cinco grupos) no setor de pneumologia e 50 (cinco grupos) no setor de gastroenterologia. Cinco amostras não apresentaram crescimento bacteriano. As cepas de bactérias identificadas pertencem aos seguintes gêneros: dois Streptococcus sp. (25\%) e um Micrococcus sp. (12\%); e às seguintes espécies: três Staphylococcus saprophyticus (37\%), um Staphylococcus aureus (13\%) e um Staphylococcus epidermidis (13\%) (Figura 1). Foi encontrado um bacilo Gram positivo.

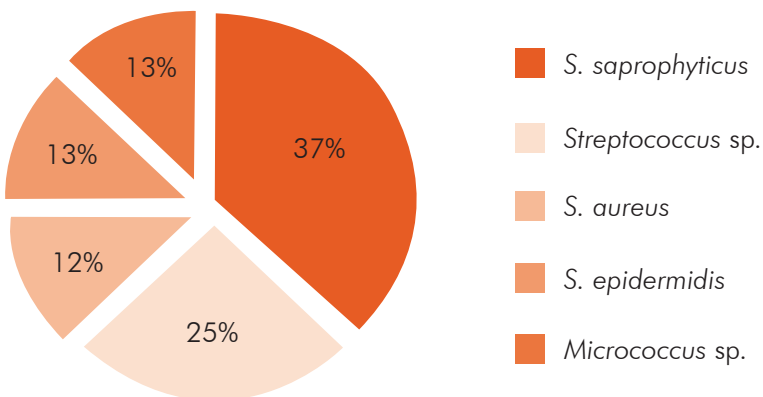

Figura 1 - Porcentagem de bactérias Gram positivas carreadas por Tapinoma melanocephalum em ambiente hospitalar de Porto Velho, Estado de Rondônia

Quanto ao método de antibiograma, foi observada resistência de 50\% das cepas à vancomicina e $83 \%$ à oxacilina, principalmente as bactérias S. saprophyticus e Streptococcus sp. coletadas no setor de gastroenterologia (Tabela 1).

Tabela 1 - Perfil de resistência das bactérias isoladas aos antimicrobianos e seu local de distribuição

\begin{tabular}{lcc}
\hline \multirow{2}{*}{ Bactéria } & \multicolumn{2}{c}{ Antimicrobiano } \\
\cline { 2 - 3 } & Vancomicina $(30 \mu \mathrm{g})$ & Oxalicina $(1 \mu \mathrm{g})$ \\
\hline S. saprophyticus ${ }^{\dagger}$ & Resistente & Resistente \\
Streptococcus sp. & Resistente & Resistente \\
S. saprophyticus* & Resistente & Resistente \\
S. epidermidis* & Sensível & Resistente \\
S. saprophyticus* & Sensível & Sensível \\
S. aureus* & Sensível & Resistente
\end{tabular}

Nota: *Setor de gastroenterologia; †Setor de pneumologia.

\section{DISCUSSÃO}

As formigas podem ser encontradas em diversos setores de um hospital, onde podem encontrar condições adequadas para sua moradia, tendo a sua estadia 
facilitada pela presença de alimentos. Esses artrópodes podem ser encontrados até mesmo em ambientes limpos, contudo, lixo e restos de alimentos facilitam o aumento de sua população ${ }^{6}$. Neste estudo, foram encontradas formigas em locais dentro do hospital, que teoricamente deveriam ser limpos, como, por exemplo, a sala de emergência. Para Maia et $\mathrm{al}^{7}$, o fato de se encontrarem formigas no ambiente hospitalar não é necessariamente sinal de sujeira, sendo que algumas espécies são atraídas por materiais estéreis, sendo consideradas indicadores de limpeza. Mesmo assim, ainda podem carrear várias espécies de bactérias patogênicas.

Outro fator preocupante é que as formigas podem ser carreadas pelo ser humano de casa até o ambiente hospitalar, podendo assim veicular microorganismos multirresistentes, aumentando o risco de infecções e da gravidade das doenças $s^{6,11}$.

Infelizmente a presença deste grupo de insetos em ambiente nosocomial não tem recebido uma maior atenção das autoridades sanitárias sobre o perigo que representa à saúde dos pacientes. Tanaka et $a^{16}$ alertam que existe uma grande variedade de espécies de formicídeos nos hospitais brasileiros, sendo que algumas delas têm uma certa afinidade por materiais estéreis e cirúrgicos e são importantes vetores de bactérias oportunistas e/ou patógenas ao ser humano. Nesse estudo, todos os formicídeos capturados são pertencentes à espécie Tapinoma melanocephalum. Segundo Nickerson et $a^{12}$, essa espécie de formiga, que no Brasil é conhecida popularmente como formiga fantasma, é um invasor proveniente da África Ocidental e tem ampla distribuição em hospitais do mundo.

Algumas características das formigas facilitam o carreamento de patógenos, como por exemplo, a presença de pelos no corpo, a escultura da cutícula e a distribuição das glândulas exócrinas, podendo servir como uma forma de adesão e sobrevivência de microorganismos em seu tegumento. Segundo Fontana et $a^{2}{ }^{2}$, dois fatores são determinantes para a infecção por bactérias: a adesão ao corpo da formiga e o fato de encontrar um ambiente adequado para se multiplicar, ou seja, com temperatura, umidade e nutrientes adequados.
Neste estudo, foi encontrada uma (7\%) cepa bacilo Gram positivo. Pereira e Ueno ${ }^{13}$, em seu estudo em um hospital universitário, encontraram $63,5 \%$ de bacilos Gram positivos e comentam que a capacidade desses bacilos em formar endósporos, permite a instalação dessas bactérias em ambientes instáveis. As formigas poderiam facilitar a sua instalação carreando os endósporos.

Para Santos et $a^{14}$, o conhecimento sobre a espécie, nicho e o modo de vida desses artrópodes podem ajudar na formulação de medidas profiláticas e de controle de infecções hospitalares, bem como o conhecimento sobre as bactérias que eles carreiam. Guilarde et $a^{15}$ constataram que $34,5 \%$ de letalidade, associada às infecções da corrente sanguínea, esta associado a bactérias oportunistas carreadas por formigas.

Teixeira et $a^{16}$, em seu estudo sobre a microbiota associada às formigas em um hospital universitário, verificaram que $27,1 \%$ das bactérias encontradas em formigas da espécie Tapinoma melanocephalum eram pertencentes ao gênero Staphylococcus spp., dentre as quais, 60\% foram resistentes à oxacilina e 100\% sensíveis à vancomicina. Dentre as cepas isoladas nesse estudo, as bactérias do gênero Staphylococcus spp. foram as mais frequentes: dentre os 13 grupos de formigas que foram coletados, cinco (38\%) tiveram a presença de bactérias pertencentes a esse gênero. Quanto ao antibiograma, a maioria das cepas encontradas nesse estudo foi resistente à oxacilina e metade à vancomicina, indicando uma baixa sensibilidade desses antimicrobianos em relação às cepas encontradas.

\section{CONCLUSÃO}

De acordo com os resultados obtidos, verificou-se a capacidade das formigas serem vetores de bactérias que podem ocasionar doenças ao ser humano, sendo que, dentre as espécies de bactérias Gram positivas isoladas, S. saprophyticus foi a que esteve mais presente nos ambientes hospitalares. Levanta-se a questão da importância do uso correto dos antimicrobianos, pois antibióticos utilizados usualmente como oxacilina e vancomicina enfrentaram alta resistência das bactérias, sendo um risco maior para o aparecimento de cepas multirresistentes.

\section{Gram-positive bacteria carried by ants in hospital environment in the City of Porto Velho, Rondônia State, Brazil}

\section{ABSTRACT}

Ants are considered vectors of several pathogens species, with high adaptability to multiple environments, and can be a risk for immunocompromised patients in hospitals. This study aimed to verify the profile of Gram-positive bacteria carried by formicids in hospital environment. The insects were collected in the emergence room, pulmonology and gastroenterology wards in a public hospital of Porto Velho, Rondônia State, Brazil from March to June, 2012. The isolates were characterized according to Gram stain, identification tests for Staphylococcus, Streptococcus, and Micrococcus genera, and susceptibility profile to antimicrobials. From 130 ants collected, 62\% of strains isolated from them were identified as Staphylococcus, 25\% as Streptococcus, and 13\% as Micrococcus. Relating to antibiotic resistance, $83 \%$ of strains were resistant to oxacillin, and $50 \%$ to vancomycin. It is concluded that ants are potential mechanical carriers of bacteria, suggesting a nosocomial infection risk and strains highly resistant to antibiotics in hospital environment.

Keywords: Disease Vectors; Cross Infection; Microbial Sensitivity Tests. 


\section{Bacterias Gram-positivas vehiculadas por hormigas en ambiente hospitalario en la Ciudad de Porto Velho, Estado de Rondônia, Brasil}

\section{RESUMEN}

Las hormigas son consideradas insectos vectores de varias especies de patógenos y presentan gran adaptabilidad a diversos tipos de ambientes. Por ese motivo pueden ofrecer riesgo a pacientes inmunodeprimidos, en ambiente hospitalario. El objetivo de este estudio fue de analizar el perfil de las bacterias Gram-positivas vehiculadas por formícidos en ambiente hospitalario. Los insectos fueron recolectados en la sala de emergencia, en el sector de neumología y en el de gastroenterología en un hospital público de Porto Velho, Estado de Rondônia, Brasil en el período de marzo a junio de 2012. Las bacterias aisladas fueron caracterizadas con relación a la coloración de Gram, pruebas para identificación de bacterias del género Staphylococcus, Streptococcus y Micrococcus y con relación al perfil de susceptibilidad a antimicrobianos. Entre las 130 hormigas capturadas, 62\% de las cepas extraídas de las hormigas fueron identificadas como pertenecientes al género Staphylococcus, 25\% Streptococcus y $13 \%$ Micrococcus. En relación a la resistencia a los antibióticos, $83 \%$ de las cepas fueron resistentes a oxacilina y $50 \%$ a vancomicina. Se concluye que las hormigas presentaron gran potencial como vehículos mecánicos de bacterias, sugiriendo el riesgo de infección nosocomial y a la permanencia de cepas con alta resistencia en el ambiente hospitalario.

Palabras clave: Vectores de Enfermedades; Infección Hospitalaria; Pruebas de Sensibilidad Microbiana.

\section{REFERÊNCIAS}

1 Freitas MR, Teixeira IRV. A formiga fantasma (Tapinoma melanocephalum F) domina os ambientes hospitalares em Guaxupé, MG. Anais do $7^{\circ}$ Congresso de Ecologia do Brasil; 2007.

2 Fontana R, Wetler RMC, Aquino RSS, Andrioli JL, Queiroz GRG, Ferreira SL, et al. Disseminação das bactérias patogênicas por formigas em dois hospitais do nordeste do Brasil. Neotrop Entomol. 2010 jul-ago;39(4):655-63.

3 Costa SB, Pelli A, Carvalho GP, Oliveira AG, Silva PR, Teixeira MM, et al. Formigas como vetores mecânicos de microorganismo no Hospital Escola da Universidade Federal do Triângulo Mineiro. Rev Soc Bras Med Trop. 2006 nov-dez;39(6):527-9.

4 Cintra-Socolowski P. Histórico sobre as pesquisas com formigas em ambientes hospitalares no Brasil. Biológico. 2007;69(Supl 2):35-8.

5 Oliveira MF, Campos-Farinha AEC. Formigas urbanas do município de Maringá, PR e suas implicações. Arq Inst Biol. 2005 jan-mar;72(1):33-9.

6 Tanaka II, Viggiani AMFS, Person OC. Bactérias veiculadas por formigas em ambiente hospitalar. Arq Med ABC. 2007;32(2):60-3.

7 Maia ZPG, Gusmão AB, Barros TF. Formigas como fator de risco para infecções nosocomiais. Rev Saud Biol. 2009 jul-dez;4(2):47-51.

8 Castro-Orozco R, Villafañe-Ferrer LM, Álvarez-Rivera E, Arco MM, Rambaut-Donado CL, Vitola-Heins GV. Staphylococcus aureus meticilino resistente en niños escolares de Cartagena. Rev Salud Publica. 2010 jun;12(3):454-63.
9 Carneiro LC, Carvalhares TT, Pesquero MA, Quintana RC, Feitosa SB, Elias Filho J, et al. Identificação de bactérias causadoras de infecção hospitalar e avaliação da tolerância a antibióticos. NewsLab. 2008;86(1):106-14.

10 Nikaido H. Multidrug Resistance in Bacteria. Annu Rev Biochem. 2009;78:119-46.

11 Pesquero MA, Elias Filho J, Carneiro LC, Feitosa SB, Oliveira MAC, Quintana RC. Formigas em ambiente hospitalar e o seu potencial como transmissoras de bactérias. Neotrop Entomol. 2008 jul-ago;37(4):472-97.

12 Nickerson JC, Bloomcamp CL, Fasulo TR. Ghost ant, Tapinoma melanocephialum (Fabricius) (Insecta: Hymenoptera: Formicidae). University of Florida; 2004. p. 1-4.

13 Pereira RS, Ueno M. Formigas como veiculadoras de microrganismos em ambiente hospitalar. Rev Soc Bras Med Trop. 2008 set-out; 4 1 (5):492-5.

14 Santos PF, Fonseca AR, Sanches NM. Formigas (Hymenoptera: Formicidae) como vetores de bactérias em dois hospitais do município de Divinópolis, Estado de Minas Gerais. Rev Soc Bras Med Trop. 2009 set-out;42(5):565-9.

15 Guilarde AO, Turchi MD, Martelli CMT, Primo MGB, Batista LJA. Bacteremias em pacientes internados em hospital universitário. Rev Assoc Med. 2007 jan-fev; $53(1): 34-8$.

16 Teixeira MM, Pelli A, Santos VM, Reis MG. Microbiota associated with tramp ants in a Brazilian University Hospital. Neotrop Entomol. 2009 Jul-Aug;38(4):537-4 1 . 